\title{
面外変形を考慮した薄板構造の剛性最大化を目的とした レベルセット法に基づくトポロジ一最適設計*
}

堀尾 仁志 ${ }^{* 1}$, 小木曽 望 ${ }^{* 2}$, 乙守 正樹 ${ }^{* 3}$, 山田 崇恭 ${ }^{* 4}$, 西脇 眞二 ${ }^{* 5}$

\section{Level set-based topology optimization of thin plate structure} for maximizing stiffness under out-of-plane deformation

\author{
Hitoshi HORIO*1, Nozomu KOGISO, Masaki OTOMORI, Takayuki YAMADA \\ and Shinji NISHIWAKI
}

${ }^{* 1}$ Department of Aerospace Engineering, Osaka Prefecture University 1-1 Gakuen-Cho, Naka-ku, Sakai, Osaka, 599-8531 JAPAN

\section{Received 25 November 2013}

\begin{abstract}
The topology optimization method using the level set method and incorporating a fictitious interface energy derived from the phase field method was proposed by part of the authors. The method has been applied to several structural and multidisciplinary design problems. However, the method has not been applied to the plate bending structural design problem using the two-dimensional plate bending element model yet, regardless that the thin plate structures are widely used in engineering applications that require lightweightness. This paper extends the topology optimization method to the thin plate structure for maximizing stiffness under out-of-plane deformation by using the thin plate bending elements based on Reissner-Mindlin theory. The structural design problem using the thin plate bending elements is formulated as the mean compliance minimization under volume constraint problem. Through simple numerical examples, effects of the proposed method are illustrated. At first, the method significantly reduces computational cost for the thin plate maximizing stiffness design problem in comparison with the three-dimensional solid model. The obtained optimum configuration is shown to be equivalent to that of the three-dimensional solid model. Then, it is shown that the advantages of the method such as high convergence property, low initial design dependency, and the effect of the regularization parameters on the complexity of the configuration are also held in the plate bending element model.
\end{abstract}

Key Words : Optimum design, Shell structure, Structural design, Finite element method,Topology optimization, Stiffness maximization

1. 緒 論

薄板構造は，その薄さのために曲げ剛性が低く，剛性，強度，座屈あるいは振動の問題を生じやすい。曲げ剛 性を大幅に向上させる方法として，一般的に，補強リブ (スティフナー) の取り付けや，ビード加工が行われてい る. その効果的な補強のために, 補強リブの最適配置に関する研究 (山崎・青木, 1989), (Cheng and Olhoff, 1981)

*論文 No.13-00834 [DOI: 10.1299/transjsme.2014dsm0054]

${ }^{* 1}$ 学生員, 大阪府立大学大学院工学研究科航空宇宙工学分野( T599-8531 大阪府堺市中区学園町 1-1)

$*_{2}$ 正員, 大阪府立大学大学院工学研究科航空宇宙工学分野

*3 正員, アイシン・エィ・ダブリュ(株) (テ444-1192 愛知県安城市藤井町高根 10 番地)

${ }^{* 4}$ 正員, 京都大学大学院工学研究科機械理工学専攻(

*5 正員, フェロー, 京都大学大学院工学研究科機械理工学専攻

E-mail: ss102033@edu.osakafu-u.ac.jp 
Horio, Kogiso, Otomori, Yamada and Nishiwaki, Transactions of the JSME (in Japanese), Vol.80, No.811 (2014)

や，面外方向に形状変更を行う最適設計に関する研究 (下田, 2013) が行われている.また, シェル構造の軽量化の ために，自由境界形状を変更する最適形状設計に関する研究 (下田, 2011) が行われている.

一方, 構造最適化の中で最も設計自由度が高い方法として, トポロジー最適設計がある (西脇他, 2013), (Bendsøe and Sigmund, 2003). この方法は，構造最適化問題を指定した設計領域内の材料分布問題へ置き換えるこ とで，構造形状だけでなく，穴の数などの形態の変化も可能とする方法であり，これまでに，均質化法に基づく手 法 (Bendsøe and Kikuchi, 1988) や, SIMP (Solid Isotropic Material with Penalization) 法 (Bendsøe, 1989) が提案され ている. 薄板構造に対しては, Pedersen は固有振動数最大化問題に対して SIMP 法を適用する手法を提案している (Pedersen, 2000). 最近では, シェル構造にSIMP 法を利用して, 固有振動数だけでなく, 減衰特性を最大化するた めに減衰材の最適配置を求める研究も行われている (Kang, et al., 2012), (Kim, et al., 2013). さらに, Mello らは薄 板構造のトポロジー最適設計の応用として, 薄膜型のピエゾ抵抗素子を平板に貼り合わせた平板に対し, 制振性 能を最大化するようなピエゾ抵抗素子の最適配置問題に応用している (Mello, et al., 2012).

均質化に基づく手法や SIMP 法はグレースケールを許容する手法である。これに対し, Maute と Ramm はト ポロジー最適設計で得られた境界をパラメータ曲線で近似しながら形状材料分布問題を有限要素分割に写像し, さらに要素分割をアダプティブに変更しながら最適形態を求める手法を提案し，シェル構造の剛性最大化問題に 適用している (Maute and Ramm, 1997). これにより，明確な外形形状が得られるが，境界形状を近似しているの であって, グレースケール問題を本質的に解決しているわけではない. グレースケール問題を解決する手法とし て, レベルセット法による形状表現に基づく手法 (Wang, et al., 2003), (Allaire, et al., 2004) が提案されている. こ の手法は，レベルセット関数のゼロ等位面により物体の外形形状を表現するため，グレースケールを含まない明 確な外形形状が得られる. Park と Youn は, レベルセット法に基づく手法をシェル構造の最適設計に適用している (Park and Youn, 2008).

しかし，これらの方法は，レベルセット関数のゼロ等位面により示す外形形状のみの変更により最適構造を得る方 法であり, 穴の創出など形態変更が許容されない.これに対し, Yamada らは, レベルセット関数による形状表現を行 いながら, 境界移動だけでなく, 穴の創出など形態変更をも可能としたトポロジー最適設計法 (Yamada, et al., 2010) を提案している。この方法では，フェーズフィールド法の考え方を導入することにより，最適設計問題を仮想的な 界面エネルギー項を含むエネルギー汎関数の最小化問題に帰着させることで, 最適化問題の正則化を行っている. この方法は, 初期構造に対する依存性が低く, さらにこの正則化の度合いを調整することにより, 構造の幾何学的 な複雑さを定性的に表すことが可能である.

しかしながら, Yamada らの提案したトポロジー最適設計法 (Yamada, et al., 2010) は, まだ, 薄板構造へ適用さ れていない, そのため, 薄板構造を三次元ソリッド要素を用いて離散化を行わなければならず, 計算時間を浪費し ていた，そこで，本論文では，薄板構造の剛性が高い構造形態を効率的に求めるために，面外変形を考慮した薄 板構造の剛性最大化を目的とした構造形態を求める設計問題に対して, 板曲げ要素を用いたレベルセット法に基 づくトポロジー最適設計法を提案する.

以下， 2 章では板曲げ要素に用いられる Reissner-Mindlin 理論について説明する．次に，3 章ではレベルセット 法による形状表現を用いたフェーズフィールド法の考え方に基づくトポロジー最適設計による剛性最大化問題の 定式化について説明する. 4 章において簡単な数值計算例により, 従来の方法との比較をしながら本論文で提案す る手法の妥当性を検証し，5 章で本論文の結論を述べる.

\section{Reissner - Mindlin 理論による薄板の面外変形}

板曲げ要素は厚さが薄いことに着目して，2 次元問題に単純化された構造要素である. Reissner - Mindin 理論は せん断変形の影響を考慮した板曲げの理論であり, 中立面に直交する平面が，変形後も平面ではあるが，直交し ないという曲げ変形を扱う (半谷, 1995). 図 1 のように, $z$ 方向の曲げ変位を $w$ とし $, x, y$ 方向の回転角度をそれ ぞれ $\beta_{x}, \beta_{y}$ と表す. 法線の長さが一定であり, 中立面の伸縮はなく, そして, 変位が長さ方向に線形分布するも のとする. 面内方向のひずみを $\varepsilon_{x}, \varepsilon_{y}$, 面内せん断ひずみを $\gamma_{x y}$, 面外せん断ひずみを $\gamma_{y z}, \gamma_{z x}$ とすると, 変位と ひずみの関係式は次式で表される.

$$
\varepsilon_{x}=z \frac{\partial \beta_{x}}{\partial x}
$$




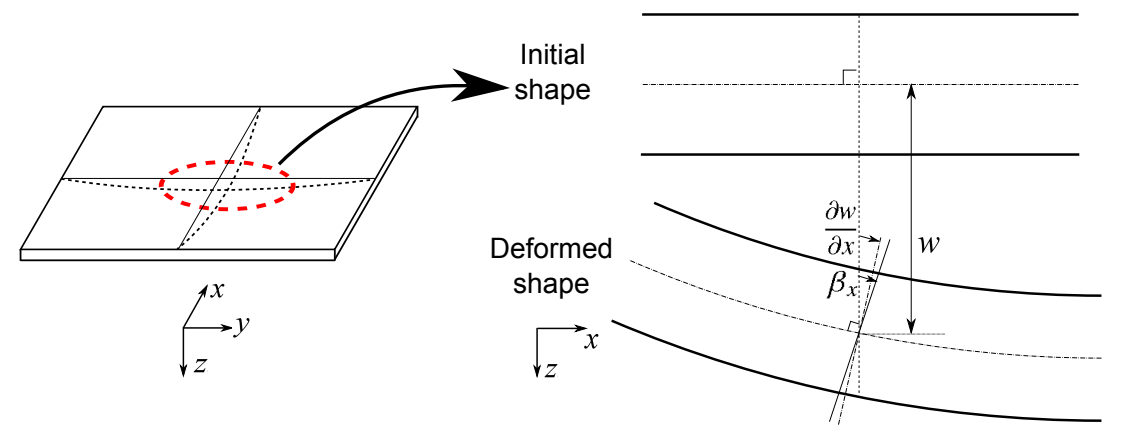

Fig. 1 Reissner-Mindlin assumption

$$
\begin{aligned}
\varepsilon_{y} & =z \frac{\partial \beta_{y}}{\partial y} \\
\gamma_{x y} & =z\left(\frac{\partial \beta_{y}}{\partial x}+\frac{\partial \beta_{x}}{\partial y}\right) \\
\gamma_{y z} & =\frac{\partial w}{\partial y}+\beta_{y} \\
\gamma_{z x} & =\frac{\partial w}{\partial x}+\beta_{x}
\end{aligned}
$$

続いて, 面内直応力を $\sigma_{x}, \sigma_{y}$, 面内せん断応力を $\tau_{x y}$, 面外せん断応力を $\tau_{z x}, \tau_{y z}$ とすると, 応力と変位の関係式 は次式となる。

$$
\begin{aligned}
\sigma_{x} & =\frac{E z}{1-v^{2}}\left(\frac{\partial \beta_{x}}{\partial x}+v \frac{\partial \beta_{y}}{\partial y}\right) \\
\sigma_{y} & =\frac{E z}{1-v^{2}}\left(\frac{\partial \beta_{y}}{\partial y}+v \frac{\partial \beta_{x}}{\partial x}\right) \\
\tau_{x y} & =G z\left(\frac{\partial \beta_{y}}{\partial x}+v \frac{\partial \beta_{x}}{\partial y}\right) \\
\tau_{y z} & =G\left(\frac{\partial w}{\partial y}+\beta_{y}\right) \\
\tau_{z x} & =G\left(\frac{\partial w}{\partial x}+\beta_{x}\right)
\end{aligned}
$$

ここで，E はヤング率，vはポアソン比であり，せん断弾性定数 $G$ は次式で表される.

$$
G=\frac{E}{2(1+v)}
$$

次に，板厚 $h ，$ 曲げ岡性 $D_{b}$ とすると，モーメントと変位の関係式は次式で表される.

$$
\begin{aligned}
M_{x} & =D_{b}\left(\frac{\partial \beta_{x}}{\partial x}+v \frac{\partial \beta_{y}}{\partial y}\right) \\
M_{y} & =D_{b}\left(\frac{\partial \beta_{y}}{\partial y}+v \frac{\partial \beta_{x}}{\partial x}\right) \\
M_{x y} & =\frac{D_{b}(1-v)}{2}\left(\frac{\partial \beta_{y}}{\partial x}+v \frac{\partial \beta_{x}}{\partial y}\right) \\
Q_{x} & =G h_{s}\left(\frac{\partial w}{\partial x}+\beta_{x}\right) \\
Q_{y} & =G h_{s}\left(\frac{\partial w}{\partial y}+\beta_{y}\right)
\end{aligned}
$$

ここで， $M_{x}, M_{y}$ は曲げモーメント， $M_{x y}$ はねじりモーメント， $Q_{x}, Q_{y}$ はせん断力， $h_{s}$ はエネルギー視点より評 価したせん断剛性補正係数であり，曲げ剛性 $D_{b}$ は次式で表される.

$$
D_{b}=\frac{E h^{3}}{12\left(1-v^{2}\right)}
$$




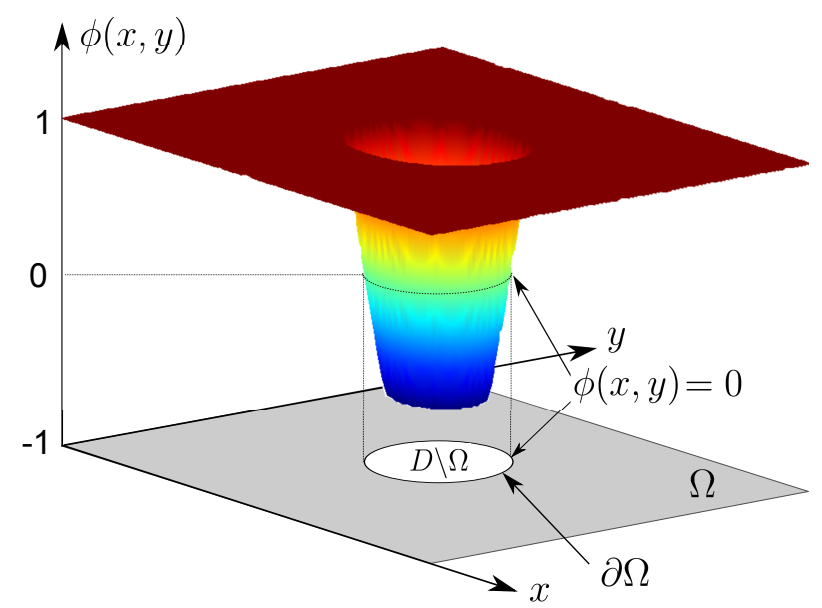

Fig. 2 Fixed design domain $D$ and level set function $\phi$

さて， 3 次元弾性体のひずみエネルギー $a(\boldsymbol{u}, \boldsymbol{v})$ は以下のように表すことができる.

$$
a(\boldsymbol{u}, \boldsymbol{v})=\frac{1}{2} \iiint\left(\sigma_{x} \epsilon_{x}+\sigma_{y} \epsilon_{y}+\sigma_{z} \epsilon_{z}+\tau_{x y} \gamma_{x y}+\tau_{y z} \gamma_{y z}+\tau_{z x} \gamma_{z x}\right) d x d y d z
$$

まず，式 (18) の積分式の第一項に注目寸る. 板厚 $h$ が一定であり, 式 (1) で $x$ 方向の回転角 $\beta_{x}$ が $z$ の関数ではな いことを考慮して $z$ で積分すると，次式が得られる。

$$
\iiint_{-h / 2}^{h / 2} \sigma_{x} \epsilon_{x} d z d x d y=\iiint_{-h / 2}^{h / 2} \sigma_{x} z \frac{\partial \beta_{x}}{\partial x} d z d x d y=\iint M_{x} \frac{\partial \beta_{x}}{\partial x} d x d y
$$

同様にして，他の項も求めると，式(18) は次式で表される.

$$
a(\boldsymbol{u}, \boldsymbol{v})=\frac{1}{2} \iint\left\{M_{x} \frac{\partial \beta_{x}}{\partial x}+M_{y} \frac{\partial \beta_{y}}{\partial y}+M_{x y}\left(\frac{\partial \beta_{y}}{\partial x}+\frac{\partial \beta_{x}}{\partial y}\right)+Q_{x}\left(\frac{\partial w}{\partial x}+\beta_{x}\right)+Q_{y}\left(\frac{\partial w}{\partial y}+\beta_{y}\right)\right\} d x d y
$$

2 次元板曲げ要素で離散化するモデルにおけるひずみエネルギーは，式 $(20)$ に基づいて求めることができる.

\section{3. レベルセット法による形状表現を用いたトポロジー最適化による剛性最大化}

\section{$3 \cdot 1$ 最適化問題の定式化}

物体で占められている領域 $\Omega$ (以下，物体領域) の存在が許容されている固定領域 $D$ (以下，固定設計領域) にお いて, 物体領域の構造最適化について考える. レベルセット法では, 図 2 に示すように, レベルセット関数と呼 ばれるスカラー関数 $\phi(x)$ を用いて，そのゼロ等位面によって物体境界を陰的に表現する．すなわち次式に示すよ うに，物体領域において正，空洞領域において負，物体の境界ではゼロとなるレベルセット関数を用いて物体の 形状表現を行う.

$$
\begin{cases}0<\phi(x) \leq 1 & \text { if } \quad{ }^{\forall} \boldsymbol{x} \in \Omega \backslash \partial \Omega \\ \phi(\boldsymbol{x})=0 & \text { if } \quad{ }^{{ } \boldsymbol{x}} \in \partial \Omega \\ -1 \leq \phi(x)<0 & \text { if } \quad{ }^{{ }} \boldsymbol{x} \in D \backslash \Omega\end{cases}
$$

ここで， $\boldsymbol{x}$ は固定設計領域の座標である。なお，本研究ではレベルセット関数に上限值と下限值を導入している が，これは目的汎関数に付加する仮想的な界面エネルギーを導入するためである.

上述のレベルセット法による形状表現を用いて, 目的汎関数を $F$, 体積制約を制約汎関数 $G$ で表す構造最適化 問題を次式で定義する.

$$
\begin{aligned}
& \underset{\phi}{\operatorname{Minimize}}: F(\Omega(\phi))=\int_{\Omega} f(\boldsymbol{x}) d \Omega \\
& \text { subject to : } G(\Omega(\phi))=\int_{\Omega} d \Omega-V_{\max } \leq 0
\end{aligned}
$$


ここで, $f(x)$ は目的汎関数の被積分関数で, $V_{\max }$ は体積の上限值である.

本研究では，フェーズフィールド理論の定式化で利用されている仮想的な界面エネルギーを導入し，式 (22)お よび式 (23)の構造最適化問題を次式に示す問題に変換する (Yamada, et al., 2010).

$$
\begin{aligned}
& \underset{\phi}{\operatorname{Minimize}}: F_{R}(\Omega(\phi))=\int_{\Omega} f(x) d \Omega+\frac{1}{2} \tau \int_{D}|\nabla \phi|^{2} d \Omega \\
& \text { subject to : } G(\Omega(\phi))=\int_{\Omega} d \Omega-V_{\max } \leq 0
\end{aligned}
$$

ここで， $F_{R}$ は正則化項を含めた目的汎関数， $\tau$ は仮想的な界面エネルギーと目的汎関数の比を示寸パラメータで, 正則化係数と呼ぶ. この值を適切に設定することにより, 最適構造の複雑さを定性的に変化させることができる. また, 本研究では, 最適化アルゴリズムを構築する段階において無次元化を行い, 正則化係数 $\tau$ の值を一意に決 定できるようにしている，詳細は文献 (Yamada, et al., 2010) を参照されたい.

ラグランジュ未定乗数法を用いて，式(24)，(25) を無制約問題に置き換える. すなわち，ラグラジュアンを $\bar{F}_{R}$, 式 (25) に関するラグランジュ乗数を $\lambda$ とすれば，上述の最適化問題は次式となる.

$$
\underset{\phi}{\operatorname{Minimize}}: \bar{F}_{R}(\Omega(\phi), \phi)=\int_{\Omega}(f(\boldsymbol{x})+\lambda) d \Omega+\int_{D} \frac{1}{2} \tau|\nabla \phi|^{2} d \Omega-\lambda V_{\max }
$$

本研究では上式を解くことにより最適構造を得る.

\section{2 時間発展方程式によるレベルセット関数の更新}

本研究では, 最適化問題を時間発展方程式を解く問題へと置き換えることにより, 設計変数であるレベルセット 関数を更新する. まず，仮想的な時間 $t$ を導入し，レベルセット関数を更新させる駆動力は，次式に示すように， ラグラジュアン $\bar{F}_{R}$ の勾配に比例するものと仮定する.

$$
\frac{\partial \phi}{\partial t}=-K(\phi) \frac{\delta \bar{F}_{R}}{\delta \phi}
$$

ここで, $K(\phi)(>0)$ は比例定数, $\delta \bar{F}_{R} / \delta \phi$ はラグラジュアン $\bar{F}_{R}$ の汎関数微分を表す. 式 (27) に式 (26) を代入し, 適 当な境界条件を設定することで, 時間発展方程式を導く。すなわち, 境界条件として, 物体領域境界であることが 指定されている境界 $\partial D_{N}$ においてはディリクレ境界条件, その他の境界においてはノイマン境界条件を与え, 固 定設計領域外部からの影響がないことを表現する. 以上より, 時間発展方程式は反応拡散方程式系として次式で 表される.

$$
\begin{aligned}
& \frac{\partial \phi}{\partial t}=-K(\phi)\left(\frac{\delta \bar{F}}{\delta \phi}-\tau \nabla^{2} \phi\right) \quad \text { in } D \\
& \frac{\partial \phi}{\partial n}=0 \quad \text { on } \quad \partial D \backslash \partial D_{N} \\
& \phi=1 \quad \text { on } \partial D_{N}
\end{aligned}
$$

なお， $\bar{F}$ は式 (22), (23) を無制約問題に置き換えた場合のラグラジュアンであり, 次式で与えられる.

$$
\bar{F}(\Omega(\phi), \phi)=\int_{\Omega}(f(x)+\lambda) d \Omega-\lambda V_{\max }
$$

\section{$3 \cdot 3$ 剛性最大化問題}

本研究では, 剛性最大化問題を考える. 線形弾性体で構成される物体領域 $\Omega$ に対して, 図 3 に示すように, 境 界 $\Gamma_{u}$ において変位 $\boldsymbol{u}_{0}$ で変位固定, 境界 $\Gamma_{t}$ に荷重 $\boldsymbol{t}$ が与えられている問題について考える. ただし, 境界 $\Gamma_{u}, \Gamma_{t}$ は, 最適設計において変化しないものとする.このとき, 体積制約の下で平均コンプライアンス $l(u)$ を最小化す る問題を考え, 目的関数を次式で定義する.

$$
F(\Omega)=l(\boldsymbol{u})
$$




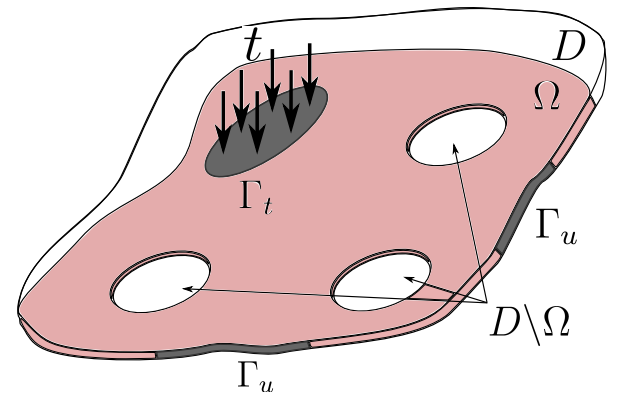

Fig. 3 Boundary condition of design problem

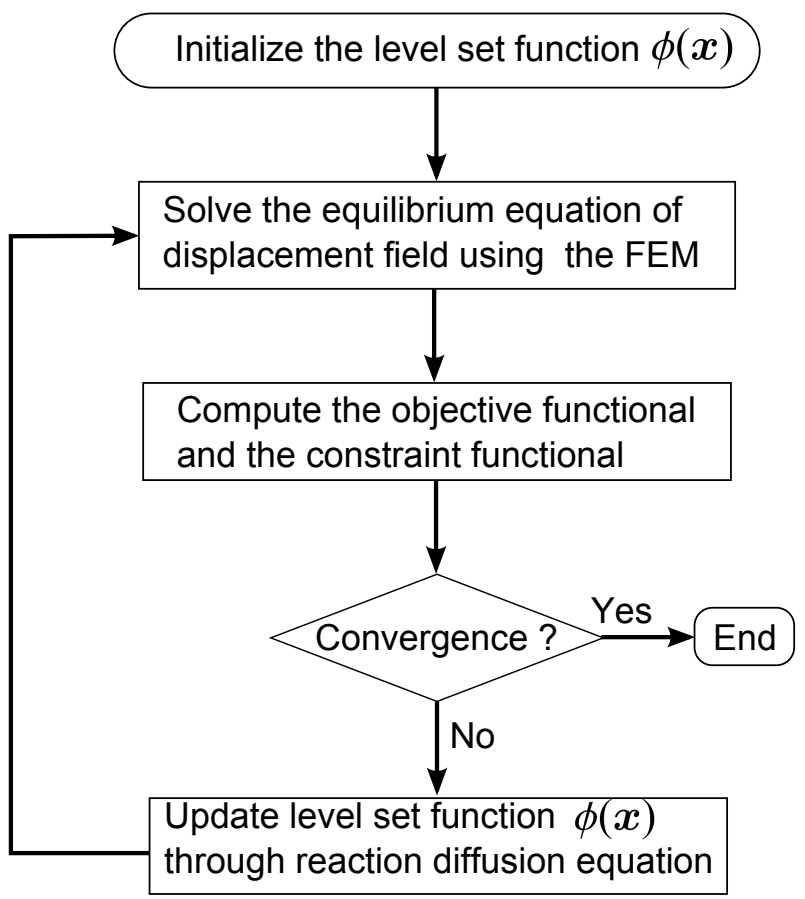

Fig. 4 Flowchart of topology optimization procedure

ここで，ひずみエネルギー $a(\boldsymbol{u}, \boldsymbol{v})$ との関係は次式で表される.

$$
\begin{aligned}
& a(\boldsymbol{u}, \boldsymbol{v})=l(\boldsymbol{v}) \quad \text { for } \forall \boldsymbol{v} \in U \quad \boldsymbol{u} \in U \\
& a(\boldsymbol{u}, \boldsymbol{v})=\int_{\Omega} \boldsymbol{\varepsilon}(\boldsymbol{u}): \boldsymbol{E}: \boldsymbol{\varepsilon}(\boldsymbol{v}) d \Omega \\
& l(\boldsymbol{v})=\int_{\Gamma_{t}} \boldsymbol{t} \cdot \boldsymbol{v} d \Gamma+\int_{\Omega} \boldsymbol{b} \cdot \boldsymbol{v} d \Omega
\end{aligned}
$$

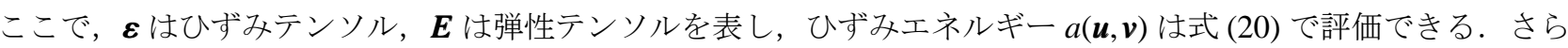
に, $U$ は以下の式にて定義される変位関数空間である.

$$
U=\left\{\boldsymbol{v}=v_{i} e_{i}: v_{i} \in H^{1}(D) \text { with } \boldsymbol{v}=0 \text { in } \Gamma_{u}\right\}
$$

\section{4 最適化アルゴリズム}

図 4 に最適化のフローチャートを示す。まず，初期構造を示すレベルセット関数 $\phi(x)$ を上限值と下限值に対す る制約を満たすように与える. 次に, 有限要素法を用いて平衡方程式を解き, 目的汎関数, 制約汎関数の值を求 める. ここで目的汎関数が収束すれば, 最適化計算を終了させる. 収束しない場合は反応拡散方程式 (28) に従い, 


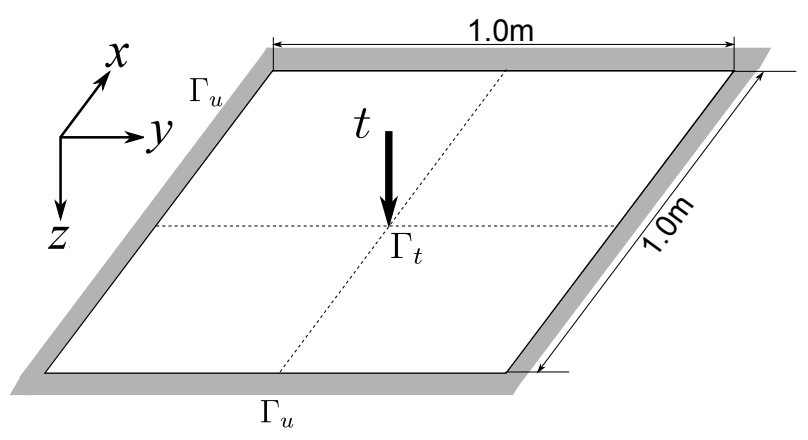

Fig. 5 Fixed design domain and boundary conditions of thin plate model

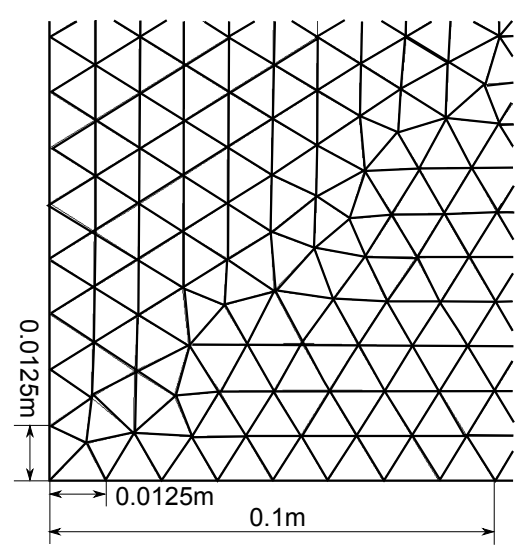

(a) Plate bending elements

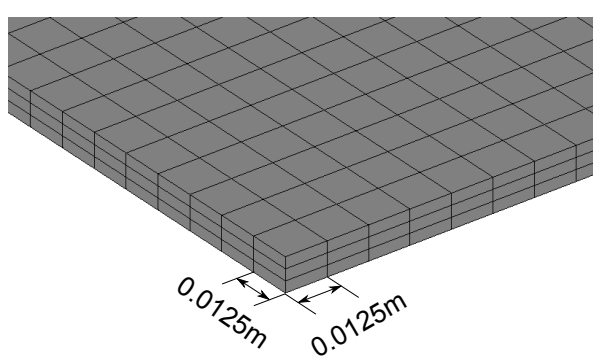

(b) Solid elements

Fig. 6 FE Model discretization

レベルセット関数 $\phi(\boldsymbol{x})$ を更新する。ただし，初期構造の体積が体積制約と大きく異なる場合，200ステップ程度 かけて，制約を満たすように修正する.

なお，変位場の解析は物体形状を陽に抽出することなく計算を行う Yamada ら (Yamada, et al., 2010) の方法と同 様の近似解法を用いる。つまり，変位場の解析における縦弾性係数は，空洞領域は十分に小さな剛性を持つ領域 とみなし，境界近傍では滑らかに推移するものとする.

\section{4. 計 算 例}

$2 つ の$ 数值例により, 本研究で提案する方法の妥当性を検証する. まず, 周辺が固定された薄板の場合について 検討する.ここでは, 最適形態を示しながら従来のソリッド要素との比較を行う. また, 得られた構造形態の妥当 性や初期構造の影響を調べる。次に, 周辺が単純支持された薄板について最適形態を検討する. 最適形態と収束 履歴を示したあと, 同様に形態の妥当性について検証する. 最後に正則化係数 $\tau$ を変化させ, 得られる最適構造 の幾何学的複雑さが定性的に調整できることを示す.

なお，薄板構造のトポロジー最適設計としては構造材料の配置よりも，構造は変化させず，それに付加する制振 材の配置問題 (Kang, et al., 2012), (Kim, et al., 2013), (Mello, et al., 2012) などが現実的な応用である.しかし，本 論文は手法の提案を目的としているため, 構造材料の配置問題を数值計算例として示す.

\section{$4 \cdot 1$ 周辺固定の場合}

図 5 で示される寸法 $1.0 \mathrm{~m} \times 1.0 \mathrm{~m}$ の正方形設計領域 $D$ が周辺固定され, 中央に $1.0 \times 10^{3} \mathrm{~N}$ の 面外荷重を受ける 場合の設計問題を考える.ここで体積制約の上限值 $V_{\text {max }}$ は固定設計領域の $50 \%$ でる $5.0 \times 10^{-3} \mathrm{~m}^{3}$ とし，正則化 係数 $\tau$ を $2.0 \times 10^{-5}$ に設定する. なお, 板厚は $0.01 \mathrm{~m}$, ヤング率 $210 \mathrm{GPa}$, ポアソン比 0.33 とし, 構造解析におい ては平均要素長 $1.25 \times 10^{-2} \mathrm{~m}$ の要素で固定設計領域を 16160 要素で分割する. 
Horio, Kogiso, Otomori, Yamada and Nishiwaki, Transactions of the JSME (in Japanese), Vol.80, No.811 (2014)

Table 1 Mesh statistics of plate bending and solid elements

\begin{tabular}{l|c|c|c|c}
\hline & Number of elements & Number of DOF & Element form & Average element size $(\mathrm{m})$ \\
\hline Plate bending & 16160 & 73524 & Triangle & 0.0125 \\
Solid & 19200 & 544341 & Cuboid & 0.0125 \\
\hline
\end{tabular}

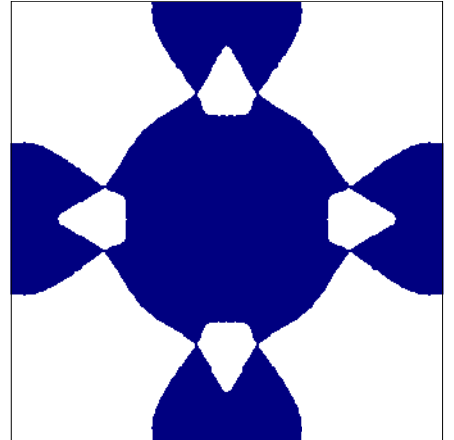

(a) Plate bending elements

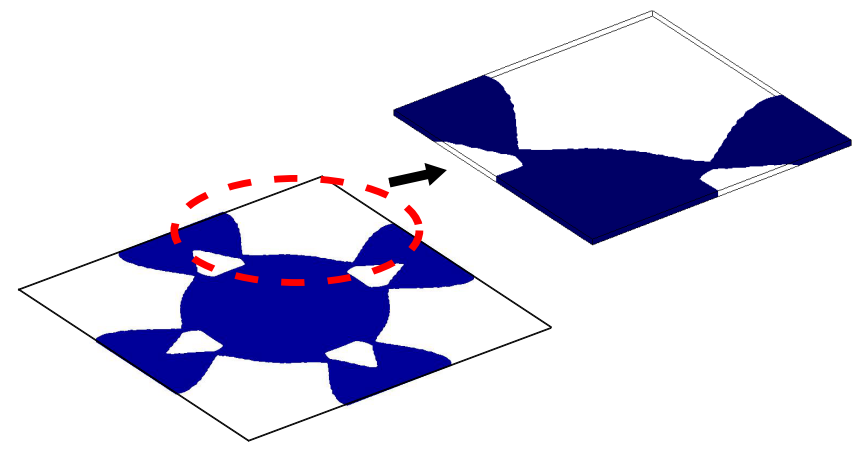

(b) Solid elements

Fig. 7 Optimal configurations using plate bending and solid elements: Both models bring the same results.

Table 2 Comparison of computational performance between plate bending and solid elements: Plate bending element model has about 40 times computational efficiency with the same objective function value as solid element model.

\begin{tabular}{l|c|c|c}
\hline & Objective function $(\mathrm{J})$ & Volume constraint $(\%)$ & ${\text { CPU time }(\mathrm{s})^{\mathrm{a}}}$ \\
\hline Plate bending & 0.1996 & 43.3 & 555 \\
Solid & 0.1984 & 43.7 & 22244 \\
\hline
\end{tabular}

${ }^{a}$ CPU : Intel(R) PentiumR III Xeon X3370

\section{4·1·1 ソリッド要素を用いたモデルとの比較}

ここでは，従来用いられていたソリッド要素によるモデルと板曲げ要素によるモデルとで，最適形態および計 算時間を比較する.この比較のため, 面内の要素の平均長を $0.0125 \mathrm{~m}$ で同じとして, 板曲げ要素は三角形要素で, ソリッド要素は六面体要素で分割する。図 6 にそれぞれの要素分割の様子を示す。それぞれの要素分割による要 素数, 自由度数などを表 1 で比較する.

得られた最適形態を図 7 に示す。なお，ソリッド要素の場合は一部を拡大したものを図 7(b) に示す。いずれも 同一の最適形態であり，中央部と周囲の辺をつなぐ部分に穴が形成され，細くなっていることが確認できる.

次に，それぞれの要素に対する最適形態の目的関数，体積，計算時間の值を表 2 で比較する. 板曲げ要素とソ リッド要素の目的関数や体積の值の差は $1 \%$ 以内であり，ほぼ同じ值である。しかし，計算時間は，板曲げ要素の 方が 40 分の 1 と圧倒的に小さく，板曲げ要素を使うことが有利であることがわかる.

最適形態に至るまでの目的関数および体積の収束履歴を図 8 で比較する。初期設計では固定設計領域すべてを 材料領域としているため, 初期段階では体積制約を満足するように体積を減少させるように変化する。このとき, 目的関数值は上昇するが, 体積が上限值に近づくにつれて目的関数の増加が緩やかになり, 収束に向かう。この傾 向はどちらの要素を用いた場合でも同じである.

これらから，板曲げ要素は形態面，数值面のどちらにおいてもソリッド要素と同等の結果を得られ，計算時間 においては大幅に減少させることができる.

\subsection{2 構造形態の妥当性}

得られた最適形態は中央部から周辺部に至る部分に穴が空いている。この形態の妥当性を簡易モデルを用いて 検証する。図 9 のように周囲から中央部に至る部材に穴が存在しない簡易モデル (Model 1) と, 穴が存在する簡易 


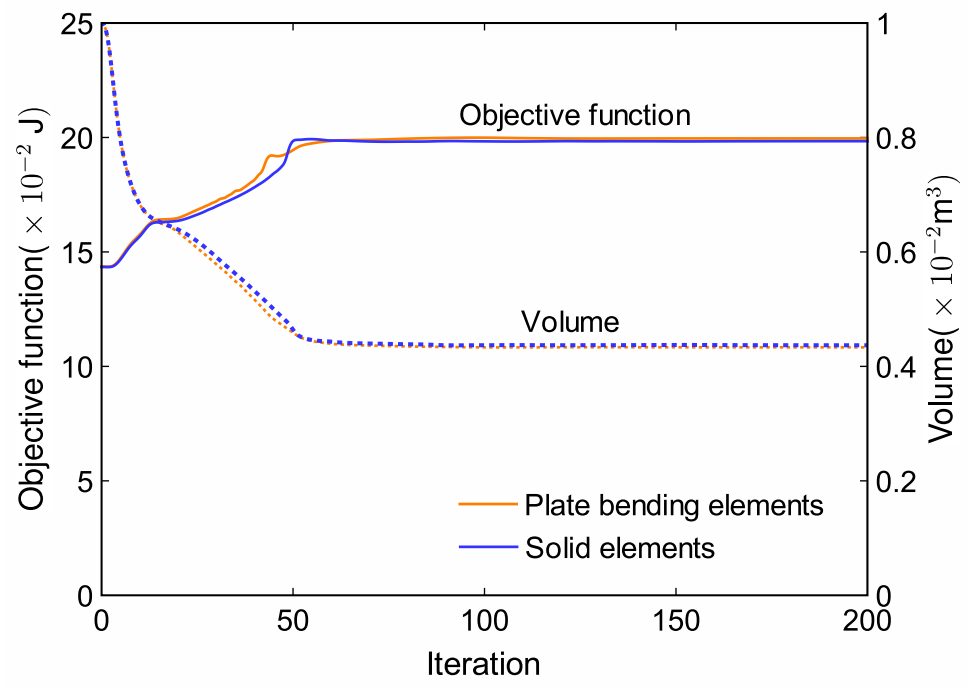

Fig. 8 Comparison of convergence histories between solid and plate bending element models: Both models have the similar convergence histories.

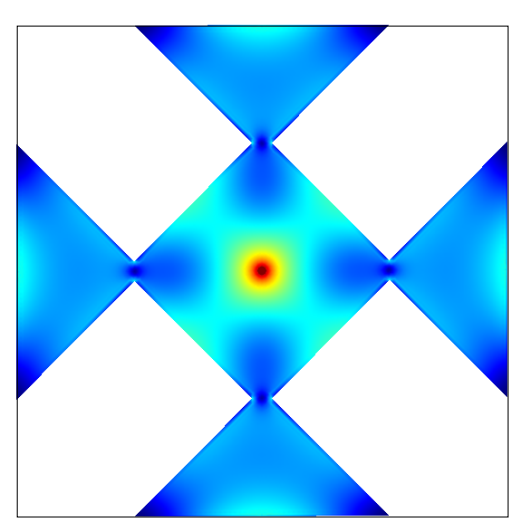

(a) Model 1

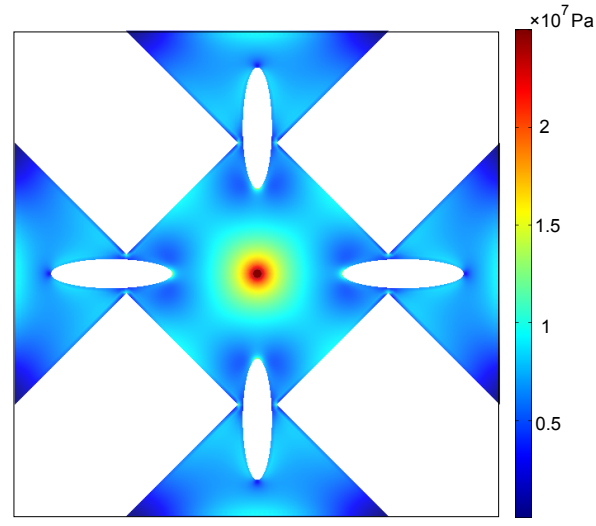

(b) Model 2

Fig. 9 Confirmation models with and without holes under edge-fixed condition that the color distribution shows von Mises stress distributions: Model with hole has higher stiffness than that without holes.

モデル (Model 2) をソリッド要素にて作成し, 応力, 変位および平均コンプライアンスの比較を行う。比較のため, 2 つの簡易モデルの体積が同じにしている.

この 2 つのモデルにおける平均コンプライアンス, ミーゼス応力の最大值，および曲げの変位の最大值を表 3 に 示す. また，それぞれのモデルでのミーゼス応力の分布図を図 9 に重ねて表示する. 表 3 より，目的関数である 平均コンプライアンスは穴が存在しないモデルよりも穴が存在するモデルのほうが小さい值をとり, 穴が存在す るモデルのほうが剛性が大きい構造であることがわかる。また，図 9 より，穴が存在しないモデルでは中央部か ら各辺に向から細くなっている部材の応力は低いことがわかる．つまり，この部分を取り除いても影響が少ない. この不要な部分に穴をあけたものが穴が存在するモデルの形態である。このことから，トポロジー最適設計で得 られた図 7 の構造形態は妥当であることがいえる.

\subsection{3 初期設計の影響}

次に初期形態の影響について検討する。この問題に対して異なる $2 つ の$ 初期形態を設定する. Case 1 は固定設計 領域がすべて物体領域により占められている場合, Case 2 は固定設計領域に 4 つの穴が開いたモデルとする. こ れらの 2 ケースに対する構造形態の変化および最適形態を図 10 で比較する.また, 最適形態の目的関数および体 
Table 3 Comparison of objective function value, maximum stress, and maximum displacement between models with and without holes under edge-fixed condition: Model with holes is superior to that without holes.

\begin{tabular}{l|c|c|c}
\hline & Objective function $(\mathrm{J})$ & Maximum stress $(\mathrm{MPa})$ & Maximum displacement $(\mathrm{m})$ \\
\hline No holes & 0.2397 & 44.14 & $4.795 \times 10^{-4}$ \\
With holes & 0.2316 & 44.31 & $4.633 \times 10^{-4}$ \\
\hline
\end{tabular}

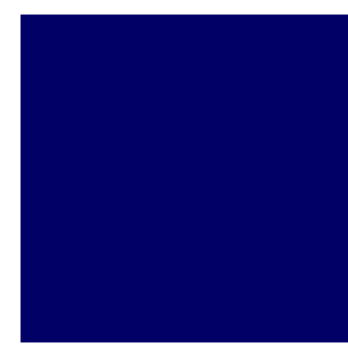

(a) Initial configuration

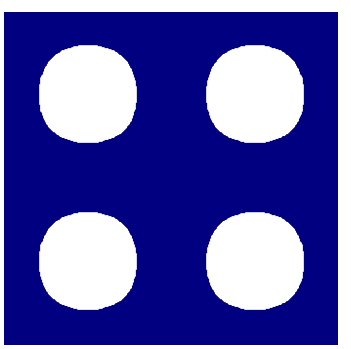

(a) Initial configuration

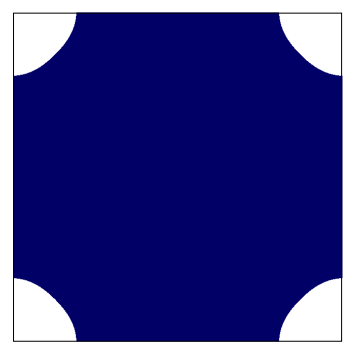

(b) Step 5

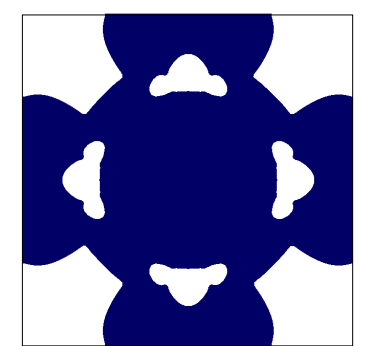

(c) Step 20

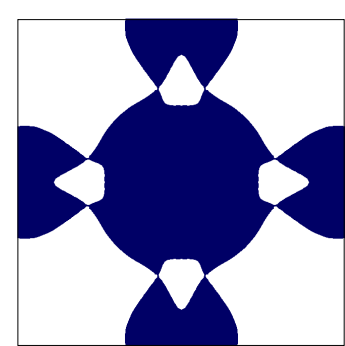

(d) Optimal configuration

Case 1

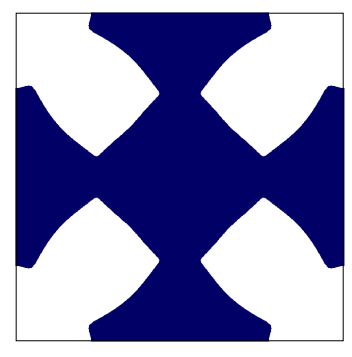

(b) Step 5

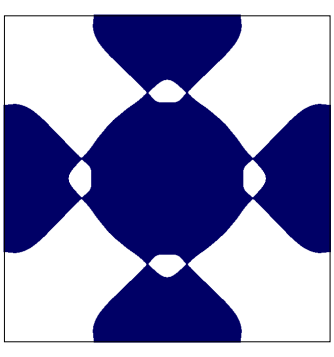

(c) Step 20

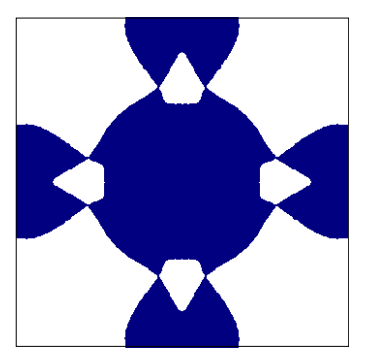

(d) Optimal configuration

Case 2

Fig. 10 Comparison of configuration histories between different initial configurations: Cases 1 and 2 converges the same optimal configurations regardless of different initial configurations.

Table 4 Comparison of Cases 1 and 2: Optimal configurations have the same performance regardless of different initial configurations.

\begin{tabular}{l|c|c}
\hline & Objective function $(\mathrm{J})$ & Volume constraint $(\%)$ \\
\hline Case 1 & 0.1996 & 43.3 \\
Case 2 & 0.1996 & 43.3 \\
\hline
\end{tabular}

積を表 4 に示す.これより，途中の形態は異なるけれど，得られた最適形態は同一で，物理的に妥当な構造が得ら れていることがわかる. 従来の手法であるソリッド要素で提案されていたのと同様，板曲げ要素の場合でも初期 状態の影響が小さいことがわかる.

\section{$4 \cdot 2$ 周辺支持の場合}

次に, $1.0 \mathrm{~m} \times 1.0 \mathrm{~m}$ の正方形設計領域 $D$ に対して, 周囲を単純支持し, 正方形の中央部に面外荷重 $1.0 \times 10^{3} \mathrm{~N}$ を 受ける場合を考える。構造解析においては, 平均要素長 $2.5 \times 10^{-3} \mathrm{~m}$ の要素で固定設計領域を 396928 要素で分割 する. 最適設計における正則化係数 $\tau$ を $1.0 \times 10^{-5}$ とし, それ以外のパラメータは周辺固定の場合と同一とする. 


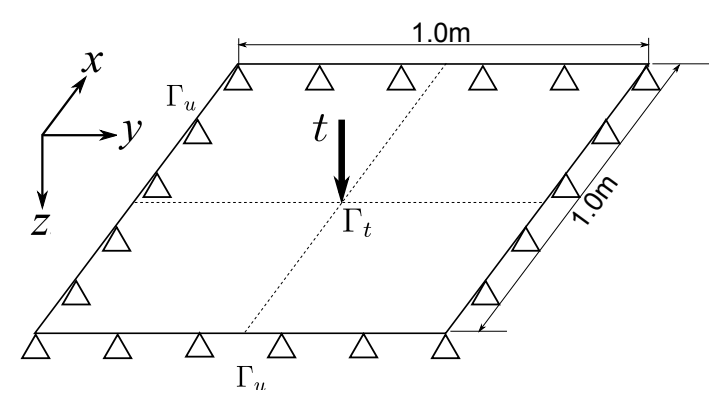

Fig. 11 Fixed design domain and boundary conditions of simply supported model

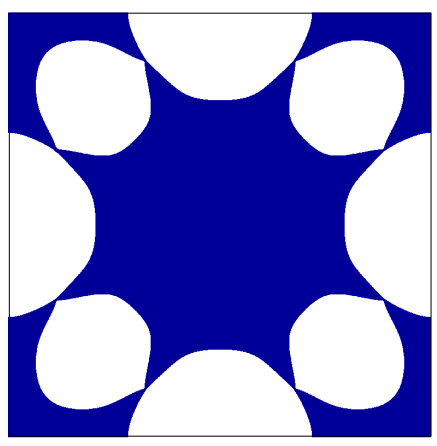

Fig. 12 Optimal configuration of simply supported model using plate bending elements

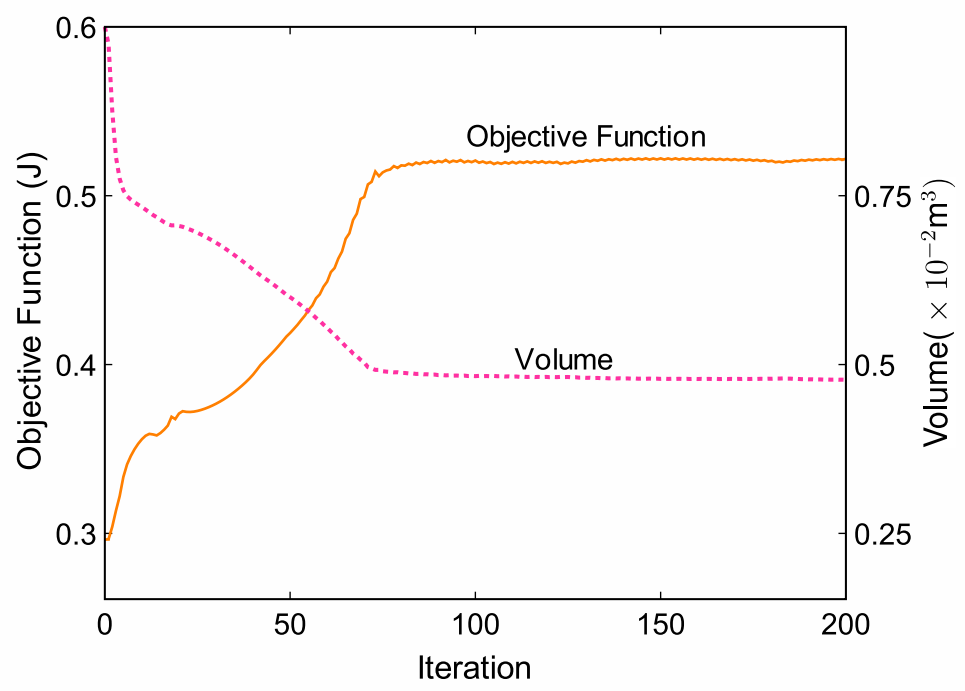

Fig. 13 Convergence history of simply-supported thin plate model using plate bending elements

\subsection{1 最適形態と収束}

板曲げ要素を用いた場合の最適形態を図 12 に示す。四隅から中央に向かって部材が配置され，中央部に向かう 部材の四隅付近に穴が創出された形態となっている。また，最適形態に至るまでの目的関数および体積の収束履 歴を図 13 に示す. 周辺固定の場合と同様に適切に収束していることがわかる.

\subsection{2 形態の妥当性}

単純支持の場合も固定支持の場合と同様に簡易モデルを用いて穴の妥当性の検討を行う。図 14 のように四隅か ら中央に至る部分に穴が存在しない簡易モデル (Model 3) と，穴が存在する簡易モデル (Model 4) を板曲げ要素を 用いて作成し，応力，変位および平均コンプライアンスの比較を行う.

この 2 つのモデルにおける平均コンプライアンス, ミーゼス応力の最大值，および厚さ方向の変位の最大值を 表 5 に示す. また，それぞれの単純支持でのモデルの応力の分布図を図 14 に重ねて表示している. 周辺固定の場 合と同様に，表 5 より，目的関数である平均コンプライアンスは，穴が存在しないモデルよりも穴が存在するモ デルのほうが小さい值をとり，穴が存在するモデルのほうが岡性が大きい構造であることがわかる．また，図 14 より，穴が存在しないモデルでは中央部から各辺に向かう細くなっている部材の応力は低くなっていることがわか る。これらの結果は周辺固定の場合と同様である.

以上より, 境界条件を変更した単純支持の場合でも, 物理的に妥当な構造が得られ, 板曲げ要素を用いた最適化 が適切に行われていると言える。 


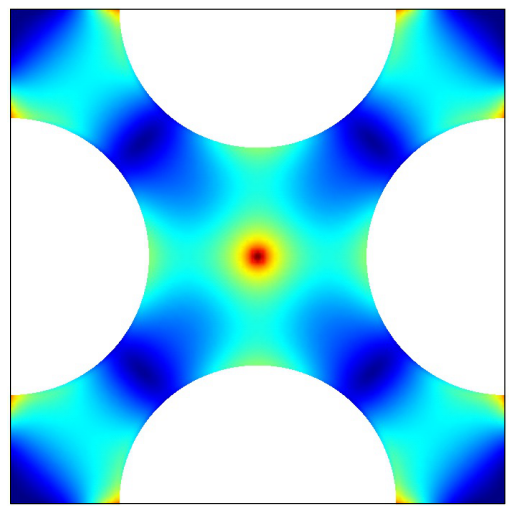

(a) Model 3

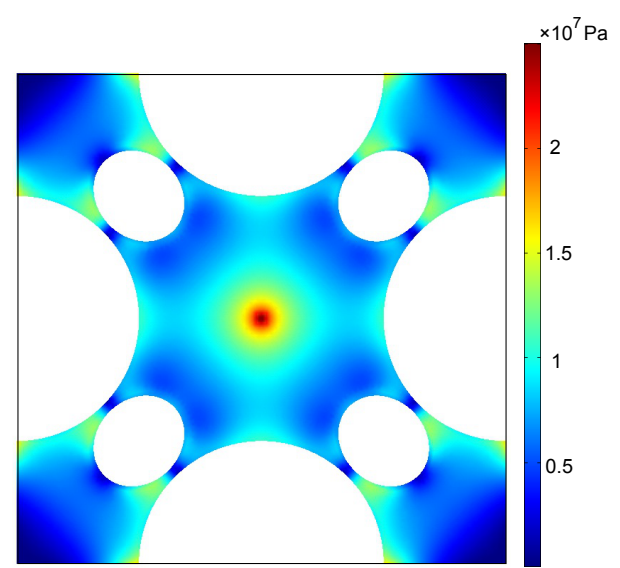

(b) Model 4

Fig. 14 Confirmation models with and without holes under simply supported condition that the color distribution shows von Mises stress distributions: Model with hole has higher stiffness than that without holes.

Table 5 Comparison of objective function value, maximum stress, and maximum displacement between models with and without holes under simply supported condition: Model with holes is superior to that without holes.

\begin{tabular}{l|c|c|c}
\hline & Objective function $(\mathrm{J})$ & Maximum stress $(\mathrm{MPa})$ & Maximum displacement $(\mathrm{m})$ \\
\hline No holes & 0.4126 & 28.33 & $8.260 \times 10^{-4}$ \\
With holes & 0.3657 & 28.14 & $7.278 \times 10^{-4}$ \\
\hline
\end{tabular}

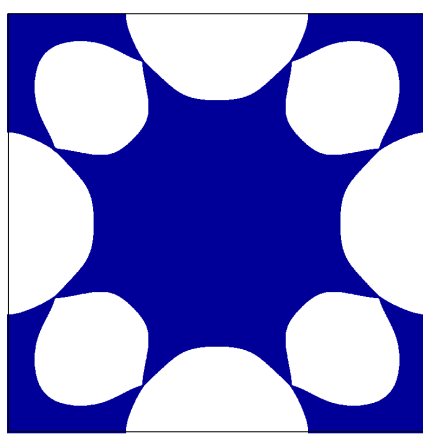

(a) $\tau=1.0 \times 10^{-5}$

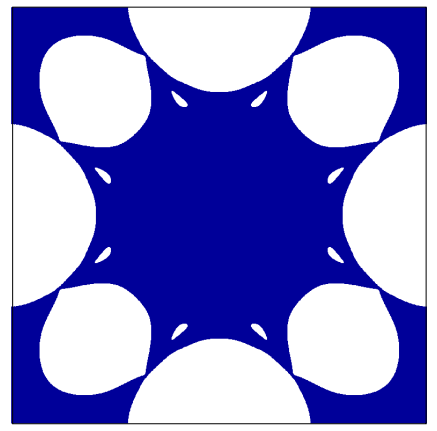

(b) $\tau=5.0 \times 10^{-6}$

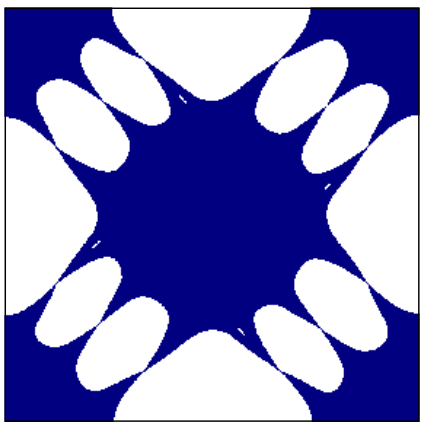

(c) $\tau=5.0 \times 10^{-7}$

Fig. 15 Effect of regularization parameter $\tau$ on the geometrical complexity of optimal configuration

\subsection{3 最適構造形態への正則化係数 $\tau$ の影響}

図 15 で正則化係数 $\tau$ を $1.0 \times 10^{-5}, 5.0 \times 10^{-6}, 5.0 \times 10^{-7}$ と設定したときの最適形態を比較する. $\tau=5.0 \times 10^{-6}$

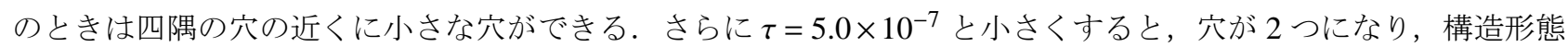
が複雑になることがわかる、これより，薄板モデルにおいてもソリッドモデルと同様に，正則化係数によって最適 構造形態の複雑さが影響を受けることがわかる.

\section{5. 結 論}

本論文では，面外方向の荷重を受ける薄板に対して，レベルセット法による形状表現を用いたトポロジー最適 化の手法を板曲げ要素モデルに適用する方法を提案し, 数值計算例を通して, 以下の点を明らかにした.

・板曲げ要素を用いた場合でも, 従来のソリッド要素と形態面, 数值面において同様の結果が得られることを 
確認した。これにより，効率的に短時間で最適形態が求められることを示した.

・面外荷重を受ける薄板に対して，提案手法により得られた最適形態が物理的に妥当であることを示した.

・提案手法においても, 初期形態の設定によらず, ほぼ同一の最適形態が得られること, 良好な収束特性を有 することを示した。 また，その繰り返し過程で穴が創出する形態変化が可能であることを示した.

\section{文献}

Allaire, G., Jouve, F. and Toader, A. M., Structural optimization using sensitivity analysis and a level-set method, Journal of Computational Physics, Vol. 194, No. 1 (2004), pp. 363-393.

Bendsøe, M. P., Optimal shape desing as a material distribution problem, Structural and Multidisciplinary Optimization, Vol. 1, No. 4 (1989), pp. 192-202.

Bendsøe, M. P. and Kikuchi, N., Generating optimal topologies in structural design using a homogenization method, Computer Methods in Applied Mechanics and Engineering, Vol. 71, No. 2 (1988), pp. 197-224.

Bendsøe, M. P. and Sigmund, O., Topology Optimization, Theory, Methods and Applications (2003), Springer-Verlag.

Cheng K. T. and Olhoff N., An investigation concerning optimal design of solid elastic plates, International Journal of Solids and Structures, Vol. 17, No. 3 (1981), pp. 305-323.

半谷裕彦, 平板の基礎理論, 彰国社 (1995).

Kang, Z., Zhang, X., Jiang, S. and Cheng, G., On topology optimization of damping layer in shell structures under harmonic excitations, Structural and Multidisciplinary Optimization, Vol. 46, No. 1 (2012), pp. 51-67.

Kim, S. Y., Mechefske, C. K. and Kim, I. Y., Optimal damping layout in a shell structure using topology optimization, Journal of Sound and Vibration, Vol. 332, No. 12 (2013), pp. 2873-2883.

Maute, K. and Ramm, E., Adaptive topology optimization of shell structures, AIAA Journal, Vol. 35, No. 11 (1997), pp. 1767-1773.

Mello, L. A. M., Takezawa, A. and Silva, E. C. N., Designing piezoresistive plate-based sensors with distribution of piezoresistive material using topology optimization, Smart Materials and Structures, Vol. 21 (2012), Paper No. 085029, pp. 1-13.

西脇眞二, 泉井一浩, 㐘池昇, トポロジー最適化 (2013), 丸善出版.

Park, K. S. and Youn, S. K., Topology optimization of shell structures using adaptive inner-front (AIF) level set method, Structural and Multidisciplinary Optimization, Vol. 36, No. 1 (2008), pp. 43-58.

Pedersen, N. L., Maximization of eigenvalues using topology optimization, Structural and Multidisciplinary Optimization, Vol. 20, No. 1 (2000), pp. 2-11.

下田昌利，板・シェル構造体の自由境界の形状設計のための最適化手法，日本機械学会論文集 A 編, Vol. 77, No. 782 (2011), pp. 1571-1582.

下田昌利, シェル構造体のフリーフォルム最適化手法, 日本機械学会論文集 A 編, Vol. 79, No. 797 (2013), pp. 60-73.

Wang, M. Y., Wang, X. M. and Guo, D. M., A level set method for structural topology optimization, Computer Methods in Applied Mechanics and Engineering, Vol. 192, No. 1-2 (2003), pp. 227-246.

Yamada, T., Izui, K., Nishiwaki, S. and Takezawa, A., A topology optimization method based on the level set method incorporationg a fictitous interface energy, Computer Method in Applied Mecanics and Enginerring, Vol. 199, No. 4548 (2010), pp. 2876-2891.

山崎光悦, 青木 昭裕, 薄板構造補強リブの最大剛性設計, 日本機械学会論文集 A 編, Vol. 55, No. 516 (1989), pp. 18841891.

\section{References}

Allaire, G., Jouve, F. and Toader, A. M., Structural optimization using sensitivity analysis and a level-set method, Journal of Computational Physics, Vol. 194, No. 1 (2004), pp. 363-393.

Bendsøe, M. P., Optimal shape desing as a material distribution problem, Structural and Multidisciplinary Optimization, Vol. 1, No. 4 (1989), pp. 192-202. 
Bendsøe, M. P. and Kikuchi, N., Generating optimal topologies in structural design using a homogenization method, Computer Methods in Applied Mechanics and Engineering, Vol. 71, No. 2 (1988), pp. 197-224.

Bendsøe, M. P. and Sigmund, O., Topology Optimization, Theory, Methods and Applications (2003), Springer-Verlag.

Cheng K. T. and Olhoff N., An investigation concerning optimal design of solid elastic plates, International Journal of Solids and Structures, Vol. 17, No. 3 (1981), pp. 305-323.

Hangai, Y., Basic Theory of Plates (1995), Shokokusha (in Japanese).

Kang, Z., Zhang, X., Jiang, S. and Cheng, G., On topology optimization of damping layer in shell structures under harmonic excitations, Structural and Multidisciplinary Optimization, Vol. 46, No. 1 (2012), pp. 51-67.

Kim, S. Y., Mechefske, C. K. and Kim, I. Y., Optimal damping layout in a shell structure using topology optimization, Journal of Sound and Vibration, Vol. 332, No. 12 (2013), pp. 2873-2883.

Maute, K. and Ramm, E., Adaptive topology optimization of shell structures, AIAA Journal, Vol. 35, No. 11 (1997), pp. 1767-1773.

Mello, L. A. M., Takezawa, A. and Silva, E. C. N., Designing piezoresistive plate-based sensors with distribution of piezoresistive material using topology optimization, Smart Materials and Structures, Vol. 21 (2012), Paper No. 085029, pp. 1-13.

Nishiwaki, S., Izui, K. and Kikuchi, N., Topology Optimization, (2013), Maruzen (in Japanese).

Park, K. S. and Youn, S. K., Topology optimization of shell structures using adaptive inner-front (AIF) level set method, Structural and Multidisciplinary Optimization, Vol. 36, No. 1 (2008), pp. 43-58.

Pedersen, N. L., Maximization of eigenvalues using topology optimization, Structural and Multidisciplinary Optimization, Vol. 20, No. 1 (2000), pp. 2-11.

Shimoda, M., Numerical optimization method for designing free-boundary shape of plate and shell structures, Transaction of the JSME, Series A, Vol. 77, No. 782 (2011), pp. 1571-1582 (in Japanese).

Shimoda, M., Free-form optimization method for shell structures, Transaction of the JSME, Series A, Vol. 79, No. 797 (2013), pp. 60-73 (in Japanese).

Wang, M. Y., Wang, X. M. and Guo, D. M., A level set method for structural topology optimization, Computer Methods in Applied Mechanics and Engineering, Vol. 192, No. 1-2 (2003), pp. 227-246.

Yamada, T., Izui, K., Nishiwaki, S. and Takezawa, A., A topology optimization method based on the level set method incorporationg a fictitous interface energy, Computer Method in Applied Mecanics and Enginerring, Vol. 199, No. 4548 (2010), pp. 2876-2891.

Yamazaki, K. and Aoki, A., Minimum compliance design technique of stiffener shape and layout for stiffened thin plate structures, Transaction of the JSME, Series A, Vol. 55, No. 516 (1989), pp. 1884-1891 (in Japanese). 